\title{
Older people's navigation of urban areas as pedestrians: Measuring quality of the built environment using oral narratives and virtual routes
}

\author{
Nigel Walford ${ }^{\mathrm{a}, *}$, Edgar Samarasundera ${ }^{\mathrm{a}}$, Judith Phillips ${ }^{\mathrm{b}}$, Ann Hockey ${ }^{\mathrm{c}}$, Nigel Foreman ${ }^{\mathrm{d}}$ \\ a Centre for Earth and Environmental Sciences Research, School of Geography, Geology and the Environment, Kingston University, \\ Penrhyn Road, Kingston upon Thames KT1 2EE, United Kingdom \\ ${ }^{\mathrm{b}}$ Centre for Innovative Ageing, School of Human and Health Sciences, Swansea University, Singleton Park, Swansea SA2 8PP, United Kingdom \\ ${ }^{\mathrm{c}}$ Department of the Built Environment, Anglia Ruskin University, Bishop Hall Lane, Chelmsford, Essex, CM1 1SQ United Kingdom \\ d School of Health and Social Sciences, Middlesex University, The Burroughs, London NW4 4BT, United Kingdom
}

\section{A R T I C L E I N F O}

\section{Article history:}

Received 26 August 2010

Received in revised form 6 December 2010

Accepted 7 December 2010

Available online 20 January 2011

Keywords:

Multimedia

Navigation

Older people

Urban design quality

Walking

\begin{abstract}
A B S T R A C T
Studies of navigation and walkability of the outdoor built environment are now common. However, few have taken a 'virtual' approach and in this study we examine the qualitative oral narratives of forty-eight older people provided whilst they watched film footage of a journey around an unfamiliar, urban landscape, and compare them with quantitative measures of the built environment. Pre-film cognitive/psychological tests were carried out, and the participants filled out a questionnaire covering relevant issues such as feelings about home area and navigational behaviour. From the oral narratives we found that signage as well as the presence of historical and distinctive buildings to be central. There was little evidence that perception of residential (familiar) neighbourhood impacted upon commentary about the unfamiliar space suggesting the findings are generalisable to the wider senior citizen demographic and transferable to other localities. We propose a prototype index for urban landscape navigation from these findings.
\end{abstract}

(c) 2011 Elsevier B.V. All rights reserved.

\section{Introduction}

There is increasing interest in the role of navigation, wayfinding and walkability of the built environment with respect to social inclusion, health outcomes and general well-being. The inclusion agenda has emphasised the importance of societal cohesion, social networks and ambience/safety issues (Bernard et al., 2001; Peace et al., 2006; Scharf et al., 2003). From a public health perspective a key aspect of this trend is the proposed relationship between the walkability of the built environment, physical activity levels and health outcomes (Leslie et al., 2007; Miles et al., 2008; Nielsen and Hansen, 2007; Pearce et al., 2009; Sugiyama et al., 2008). With an ageing population there is an extra imperative to investigate the needs of older people. Older adults are recognised to be a demographic group with feelings of social exclusion being particularly prevalent especially amongst groups of lower socio-economic status (Smith and Hancock, 2004; Stillman et al., 2009) and in which very low levels of physical activity are common (Lee and Park, 2006).

\footnotetext{
* Corresponding author. Tel.: +44 0208417 2512; fax: +44 02084172497.

E-mail addresses: N.Walford@kingston.ac.uk (N. Walford), E.Samarasundera@kingston.ac.uk (E. Samarasundera), Judith.E.Phillips@swansea.ac.uk (J. Phillips),Ann.Hockey@anglia.ac.uk (A. Hockey), N.Foreman@middx.ac.uk (N. Foreman).
}

Studies involving older people demonstrate the need to improve the design of the built environment (Burton and Mitchell, 2006; Stahl et al., 2008; Valdemarsson et al., 2005). Factors of particular relevance to older people include pavement quality and ease of street crossing (Scharf et al., 2002); mental health research also suggests that improvements in the built environment positively impact upon older people more than other demographic groups. A number of measures of built environment quality now exist covering a range of phenomena from general neighbourhood satisfaction (Day, 2008) to street audits (Allen and Clark, 2008; Cunningham et al., 2005; Ewing et al., 2006; Giles-Corti et al., 2006, 2008; Inclusive Design for Getting Outdoors, 2009a,b; Michael and McGregor, 2005; Millington et al., 2009). There is a growing array of measures of street walkability across a number of different countries. A pivotal approach upon which others have been based is the Systematic Pedestrian and Cycling Environmental Scan (SPACES) developed by Pikora et al. (2003, 2006) in Australia using Delphi methods, and focusing on four key aspects of the built environment: aesthetics, amenities, function and safety.

The SPACES approach has since provided the basis for at least two newer methods, the Scottish Walkability Assessment Tool (Millington et al., 2009) and the Senior Walking Environmental Assessment Tool (SWEAT) (Cunningham et al., 2005). The former differs from SPACES in that its sole emphasis is upon walking and in that it is tailored to the more densely structured contexts 
of north European cities. It puts less emphasis for example on the presence/absence of continuous pavements which are fairly standard features of north European urban areas, and more on pavement quality. Millington et al. (2009) also found in the same study that only 18 of 119 items hypothesised to be measures of walkability were of direct use. This indicates the value of further investigating walkability measures in greater depth, especially with older people, since the study's participants were aged 18-65 years and so the walkability assessment tool is not tailored to the needs of older citizens. In contrast the original SWEAT tool has now been revised as SWEAT-R (Michael and McGregor, 2005) and is specifically tailored to older people, who were involved in its construction. The method (Michael et al., 2009) involves a structured questionnaire comprising 154 variables, divided into eight sections, which are used by researchers to audit and quantify built environment quality. The sections cover crossings, pavement buffer zones, land use mix, public spaces, pavements, traffic lane characteristics and signage for drivers, street life and built environment maintenance. However, it was developed for North American urban contexts, which are more expansive than cities and towns of northern Europe, and its developers (Cunningham et al., 2005) recognised the method should be tailored by identifying the most locally relevant variables. Hence in this paper we investigate which variables of SWEAT-R are most relevant to British urban contexts.

However, the use of walkability measures alone typically leaves out many of the aesthetic and structural aspects of the built environment, although there are several measures of built environment design which could be linked to these in a complementary way. A notable urban design measure used in North America is the urban design quality (UDQ) index (Clemente et al., 2005; Ewing et al., 2006). As with other measures of urban design (e.g. Elsheshtawy, 1997; Punter, 2007; Stahle, 2010) the purpose of UDQ is to capture aspects of the built environment pertaining to facets directly relevant to people's emotive responses to aesthetics and structure in urban landscapes. The UDQ measure in its core form consists of five sections covering a sense of enclosed space (enclosure and transparency), items which match the sizes and dimensions of people (human scale), memorability of a locality (imageability) and the visual richness of places (complexity). Enclosure includes variables such as presence of walls, long sight lines and observable sky; this section in many respects touches on many issues and variables included within the transparency section. By human scale the developers of UDQ refer to physical environment aspects such as the presence of potted plants and flower beds, and street furniture. Imageability refers to aspects which can produce a lasting positive impression such as historic or distinctive buildings and landmarks. The last section of UDQ, complexity, covers items relating to diversity in both the built and social environments of landscapes.

Even though there is now much interest in the effects of built environment design upon physical activity, studies of walking behaviour yield conflicting results, some showing no association and others a strong one (Collins et al., 2009; Rundle et al., 2008; Santos et al., 2009; Suminski et al., 2008; Tucker et al., 2009). It has been suggested that this is largely due to variations in study design and that research involving self-reporting of activity levels are likely to result in over-estimates of walking behaviour (WendelVos et al., 2003). As a result rather than using self-reporting many studies have used pedometers in conjunction with global positioning systems and the International Physical Activity Questionnaire to estimate levels of walking, often with the purpose of assessing the relationship between physical activity and obesity (Fromel et al., 2009). Whilst these methods have clear value with respect to cause-and-effect understanding, there are limitations to using this approach to assist with designing urban environments that encourage physical activity, both in the context of older persons specifically and also in terms of identifying people's 'real-time' perceptions of built environments. With regard to older people there is the difficulty of capturing sufficient field data on older citizens' walking preferences due to restrictions on actual walking behaviour on account of social exclusion issues as well as legacies of past spatial planning and urban design. This has implications for collecting 'real-time' field data on older people's perceptions as even capturing audio commentaries on present walking behaviour will largely be restricted to those routes regularly used by older people. An alternative approach could be to use the viewing of virtual built environments to identify older people's perspectives and responses to environmental triggers. This approach has previously been used in the context of building interiors (Foreman et al., 2005).

\section{Methods}

In this paper we propose a mixed methods approach (see Creswell and Plano Clark, 2006) using viewing of virtual exterior environments in combination with oral narratives from older people and street audits carried out by researchers to identify their needs and preferences. These methods are applied using the case study of navigation around an unfamiliar town, a key element of the Older People's Use of Unfamiliar Space (OPUS) project. The term 'virtual environment' should be used with some caution since it commonly refers to simulations that can be explored independently by participants using an interactive device. Such simulations have been used to investigate some aspects of spatial memory decline with age (Head and Isom, 2010; Jansen et al., 2010). The approach adopted in this study, presentation of a video recorded route, ensures that although the experience is quite authentic and realistic everyone gets the same sensory experience and it is not affected by the difficulties that some older people have in using computers and interface devices. This approach might be described as passive virtual transportation, like travelling on a bus or in a wheelchair, viewing a visualisation of a real environment. Sjolinder et al. (2005) mention similarities between acquiring spatial knowledge in real and virtual environments and suggest older people are likely to need more time to process information and are less likely to use configurational (map-like) knowledge.

We use the demographically tailored SWEAT-R and the UDQ system in conjunction with oral narratives provided by participants during the viewing of a filmed route to provide direct insight from of older people themselves (Burton and Mitchell, 2006; Glass and Balfour, 2003). This helps to identify which SWEAT-R and UDQ variables are most pertinent to older people's navigation in a north European context, especially British urban areas. Thus the rationale for combining oral narratives with quantitative measures of built environment quality is to identify systematic correlations between the two data types in order to pinpoint those aspects of the existing walkability and urban design measures that are most important to older people in their own 'voices'. More specifically there are important research questions as to whether a navigational index for older people can be produced by extracting relevant variables from walkability and design measures, and whether an older person's perceptions of his/her familiar home neighbourhood combined with his/her individual characteristics (in effect pedestrian type) impact upon theoretical navigational behaviour in an unfamiliar landscape. A navigational index based jointly on walkability and design measures and informed by older people's ‘voices' is important in terms of facilitating visitor wayfinding in an unfamiliar landscape, whilst the latter has already been recognised within the 
context of walkability using space syntax techniques (Stonor et al., 2003).

\subsection{Participant recruitment, pre-film procedures and virtual route viewing}

To aid in assessing the potential walking behaviour amongst older people, 44 participants aged over 60 years from Swansea in south Wales provided oral commentary on both navigation and general landscape whilst being shown footage of a virtual route around Colchester in the east of England. The choice of two towns approximately $400 \mathrm{~km}$ apart was to ensure the participants were as unfamiliar as possible with the study area. Ambulatory participants, without pre-existing diagnosis of cognitive impairment, were recruited through older people's organisations (U3A and 50+) in Swansea. Overall the average ages of 18 male and 26 female participants were 70.3 and 71.1 years and the average number of years they had lived in the Swansea area were, respectively, 36.7 and 36.8 years. Prior to film viewing the participants took part in spatial orientation tests to aid in assessing whether their cognitive/spatial abilities might impact upon the oral narratives they were about to provide. Two measures were used, the Cognitive Abilities Screening Instrument (CASI) and Direct Assessment. Average scores for male and female participants using CASI were 96.3 and 97.0, respectively. The CASI test (Teng et al., 1994) was originally developed to make cross-cultural comparisons of dementia and makes a quantitative assessment on a scale of $0-100$ of a person's abstraction, language, memory and visual abilities. The Direct Assessment involved basic physical spatial orientation tests within a room, and participants were classified qualitatively on the basis of either needing assistance or not. There was no evidence of male-female differentials in these tests. Participants were separated into two groups in respect of direct assessment of their ability to follow directions in an unfamiliar setting. There was no significant differences between these groups regarding gender, age and cognitive abilities (no difficulty with directions male and female average ages were 69.3 and 70.5 years; required assistance with directions male and female average ages were 71.4 and 71.8 years).

Participant characteristics were also summarised according to a pre-film viewing questionnaire they filled out covering perceptions of their residential neighbourhood, social networks and navigational awareness. Each section consisted of questions scored on a five-point psychometric Likert scale. The residential neighbourhood section consisted of 35 variables and included aspects such as neighbourhood services, crime, traffic and aesthetics. The section on social networks consisted of 12 questions relating to relationships with others including frequency of contacts with friends/relatives, as well as emotional and practical support within social circles. The navigational awareness section was split into two sub-sections of questions, the first covering general navigation and the second relating to mental mapping facility. Hartley et al. (2003) have shown that familiar and novel routes are differently encoded in the brain and so repeated exposure to a route and virtual or real exploration of new a new one could indicate whether older people construct map-like configurations to represent unfamiliar environments. The items within the first sub-section examined matters such as strategies used in wayfinding and feelings of anxiety about unfamiliar spaces. The second sub-section looked at variables relevant to maintaining a general sense of direction within urban landscapes. The pre-film questionnaire categories were also chosen to reflect broad content correspondence with as many of the variables in the SWEAT-R and UDQ measures as possible. For example the section on residential neighbourhood included items on types of residence and amenities, reflecting the SWEAT-R section on land uses/buildings.
Viewing the virtual route involved participants watching a 31 min pedestrian walk around central Colchester that included a range of settings, such as a busy high street, residential areas, bus stops, steep slopes and a train station (see Fig. 1). Participants viewed the route in the presence of a researcher who introduced the procedure as follows:

I am now going to show you a short film taken when I visited another town.

The walk around town starts and finishes at the town train station. I would like you to imagine you are the person walking down the street.

Tell me about the walking conditions, landmarks and any other information that you think might be important.

Describe the streets and buildings and how you feel along the way. Please feel free to talk about anything you see.

Before we start do you have any questions?

In this way the participants were encouraged to talk about their experience of the unfamiliar route and their oral narratives were digitally recorded and later transcribed.

\subsection{Relating oral narratives to built environment measures}

The content of the narratives provided by each participant for the duration of his/her virtual 'walk around town' was analysed and classified into SWEAT-R and UDQ categories, which were expanded to include additional comments falling outside of the scope of these existing built environment walkability and urban design tools. This enabled a direct comparison to be made between the qualitative oral narratives and quantitative SWEAT-R and UDQ measures. Each oral narrative was divided into 31 min-long segments and keywords were identified in each segment. Keywords were used rather than the professional terminology contained in the full description of the SWEAT-R/UDQ items; since they related more closely to the everyday use of language by members of the public. This reflected the emphasis on incorporating the 'voices' of older people into the research process and design.

A coding system was developed that combined the numerical frequency of mentioning a particular keyword (e.g. comments about the quality of a stretch of pavement) with whether the reference was positive, neutral, negative or not mentioned in each segment. For each single instance of a neutral comment on a keyword a value of 1 was assigned; a positive mention was coded as 2 , a negative mention as -1 and no mention resulted in a coding of 0 . For any individual segment of the route, there could be multiple comments on the same keyword or variable in which case a numerical prefix indicating the number of mentions was attached to the code. For example if residential buildings were referred to twice positively in a segment a code of 22 would be assigned. In more complex situations where, for instance, a participant may have viewed both aesthetically pleasing and displeasing residential buildings, and made a single comment on each, coded as 12 and -12 , respectively, resulting in an overall score of 0 being assigned to that variable for the segment in question. Hence codes for single mentions would be $-11,11$ and 12 ; those for double mentions would be $-21,21$ and 22 ; and triple mentions would be $-31,31$ and 32 ; and so on. Where conflicting views were given by an individual participant for a specified variable during a 1-min section, for example two positive double mentions giving 22 and a single negative mention giving -11 , the combined result for that time slice would be 31 . 


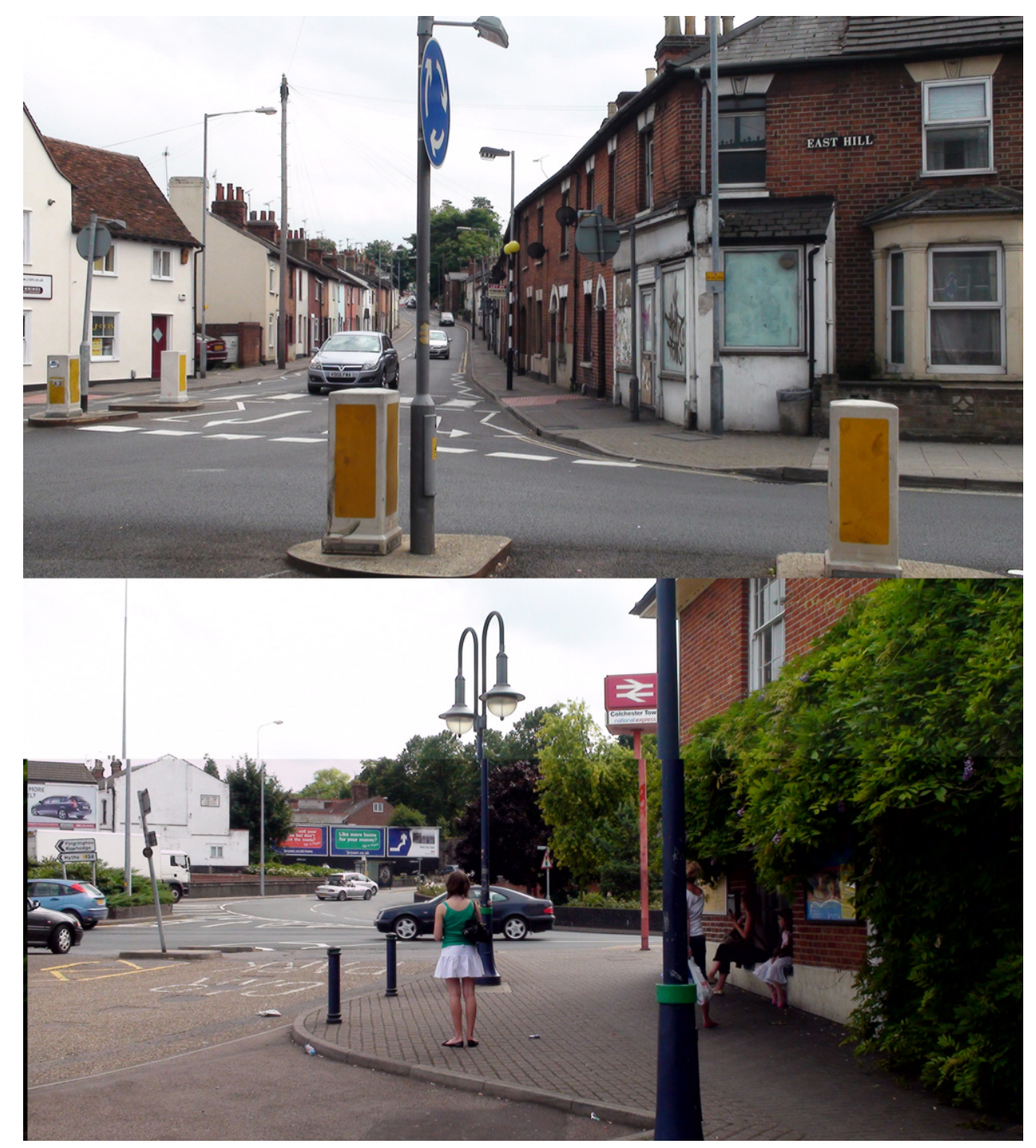

Fig. 1. Sample images from the Colchester walking route: Colchester Town rail station and Brook Street/East Hill crossing.

\section{Results}

Analyses of group mean scores and ranges for each pre-film questionnaire and built environment category were made; means calculated for the pre-film questionnaire and oral narrative outcomes were adjusted or weighted to reflect the number of variables in each category. This was followed by assessment of the extent of group-level correlation between mean scores for corresponding sections in the pre-film questionnaires and the built environment measures, using the Pearson's Product-Moment Correlation Coefficient (PMCC).

In terms of the pre-film viewing cognitive and psychological tests no correlation between the Direct Assessment and CASI tests, and the oral narratives was in evidence. The mean scores for the pre-film questionnaire and narrative categories (Table 1) show that in terms of individual spatial behavioural traits, general faculties in navigational awareness appeared stronger than abilities in specifically constructing mental maps (adjusted mean scores 3.45 and 1.86 , respectively), though the former showed wider variation amongst the group. With respect to home neighbourhood the overall impression of the area produced the highest adjusted mean (3.26), and although that for amenities was similar (3.17) it produced a wider range of Likert scale outcomes. Mean scores for social networks and worrisome aspects of home neighbourhood showed moderate Likert scale scores with little variation within the sample. Narratives on the built environment analysed using the coding system outlined previously produced clear patterns in the relevance of each category to navigation in terms of mean scores; however, there was wide variability amongst the participants as indicated by the value ranges. The topics of signage and turnings/junctions, neither of which is present in the SWEAT-R and UDQ measures, proved to be the most common reference points in the virtual navigation. Amongst the SWEAT-R categories land use mix yielded the highest mean and widest range of scores, whilst for UDQ imageability and complexity yielded especially high means.

Table 2 summarises associations between group mean scores pre-film questionnaire sections and their corresponding scores for oral narrative sections. Perceptions of home neighbourhood showed some weak correlation with commentaries on aspects of the unfamiliar environment relating to maintenance of the built environment (SWEAT-R maintenance) $(-0.28)$, distinctiveness of buildings (UDQ imageability) $(+0.28)$ and visual variety of the wider built environment (UDQ complexity) $(+0.30)$, but little to no evidence of association with other aspects of SWEAT-R and UDQ which had corresponding questions in the pre-film questionnaire. Neither questionnaire category relating to navigation yielded an association with commentary on signage, turnings or junctions. Notably no correlation was found between participant social 
Table 1

Group means and ranges for pre-film questionnaire and oral narrative categories.

\begin{tabular}{|c|c|c|c|}
\hline & Mean & Range & Adjusted mean \\
\hline \multicolumn{4}{|l|}{ Pre-film tests } \\
\hline Cognitive Abilities & 96 & $90-100$ & $\mathrm{~N} / \mathrm{A}$ \\
\hline \multicolumn{4}{|l|}{ Screening Instrument (CASI) } \\
\hline Direct Assessment & 1.7 & $1-2$ & $\mathrm{~N} / \mathrm{A}$ \\
\hline International Physical & 2.0 & $1-3$ & $\mathrm{~N} / \mathrm{A}$ \\
\hline \multicolumn{4}{|l|}{ Activity Questionnaire (IPAQ) } \\
\hline \multicolumn{4}{|l|}{ Pre-film questionnaire } \\
\hline $\begin{array}{l}\text { Home neighbourhood } \\
\text { residential mix }\end{array}$ & 6 & $4-6$ & 0.94 \\
\hline $\begin{array}{l}\text { Home neighbourhood } \\
\text { amenities }\end{array}$ & 73 & $42-102$ & 3.17 \\
\hline General home & 46 & $34-57$ & 3.26 \\
\hline \multicolumn{4}{|l|}{ neighbourhood traits } \\
\hline Worrisome home & 19 & $18-22$ & 1.91 \\
\hline \multicolumn{4}{|l|}{ neighbourhood traits } \\
\hline Social networks & 26 & $20-33$ & 2.17 \\
\hline General navigational & 72 & $50-90$ & 3.45 \\
\hline \multicolumn{4}{|l|}{ awareness } \\
\hline Mental maps & 63 & $58-78$ & 1.86 \\
\hline \multicolumn{4}{|l|}{ Oral narratives } \\
\hline Sense of place comments & 29 & $-63-186$ & 5.8 \\
\hline Signage & 32 & $-19-126$ & 32.0 \\
\hline Turnings/junctions & 82 & $22-186$ & 41.0 \\
\hline SWEAT-R & 141 & $34-303$ & 7.8 \\
\hline \multicolumn{4}{|l|}{ crossings/buffers/streets } \\
\hline SWEAT-R land use mix & 261 & $110-537$ & 21.8 \\
\hline SWEAT-R public spaces & 5 & $0-24$ & 2.5 \\
\hline SWEAT-R pavements & 18 & $-65-101$ & 4.5 \\
\hline SWEAT-R street life & 44 & $0-100$ & 7.8 \\
\hline SWEAT-R maintenance & -24 & $-88-24$ & -6.0 \\
\hline UDQ human scale & 15 & $-20-69$ & 3.8 \\
\hline UDQ transparency & 11 & $0-43$ & 5.5 \\
\hline UDQ imageability & 282 & $91-418$ & 47.0 \\
\hline UDQ complexity & 118 & $12-216$ & 39.3 \\
\hline UDQ enclosure & 11 & $0-43$ & 3.7 \\
\hline
\end{tabular}

Source: study data.

Table 2

Pearson's product-moment correlation coefficients for pre-film questionnaire category correlations with corresponding oral narrative categories.

\begin{tabular}{|c|c|}
\hline Corresponding questionnaire and narrative categories & $\begin{array}{l}\text { Pearson } \\
\text { correlation } \\
\text { coefficients }\end{array}$ \\
\hline $\begin{array}{l}\text { General home neighbourhood traits with comments on } \\
\text { crossings/buffers/streets }\end{array}$ & +0.00 \\
\hline $\begin{array}{l}\text { General home neighbourhood traits with comments on } \\
\text { maintenance }\end{array}$ & -0.28 \\
\hline $\begin{array}{l}\text { General home neighbourhood traits with comments on } \\
\text { pavements }\end{array}$ & +0.10 \\
\hline $\begin{array}{l}\text { General home neighbourhood traits with comments on } \\
\text { public spaces }\end{array}$ & +0.14 \\
\hline $\begin{array}{l}\text { General home neighbourhood traits with comments on } \\
\text { UDQ complexity }\end{array}$ & +0.30 \\
\hline $\begin{array}{l}\text { General home neighbourhood traits with comments on } \\
\text { UDQ enclosure }\end{array}$ & -0.02 \\
\hline $\begin{array}{l}\text { General home neighbourhood traits with comments on } \\
\text { UDQ human scale }\end{array}$ & +0.22 \\
\hline $\begin{array}{l}\text { General home neighbourhood traits with comments on } \\
\text { UDQ imageability }\end{array}$ & +0.28 \\
\hline $\begin{array}{l}\text { General home neighbourhood traits with comments on } \\
\text { UDQ transparency }\end{array}$ & +0.06 \\
\hline $\begin{array}{l}\text { General navigational awareness with comments on } \\
\text { navigation signage }\end{array}$ & -0.05 \\
\hline $\begin{array}{l}\text { General navigational awareness with comments on } \\
\text { turnings/junctions }\end{array}$ & -0.42 \\
\hline $\begin{array}{l}\text { Home neighbourhood amenities with comments on land } \\
\text { use mix }\end{array}$ & +0.32 \\
\hline Mental maps with comments on navigation signage & -0.14 \\
\hline Mental maps with comments on turnings/junctions & +0.12 \\
\hline Social networks with comments on street life & +0.02 \\
\hline $\begin{array}{l}\text { Worrisome aspects of home neighbourhood with sense of } \\
\text { place comments }\end{array}$ & +0.14 \\
\hline
\end{tabular}

Source: study data. networks and narratives on human interactions observed in the virtual journey nor was any relationship observed between troublesome aspects of home locale (e.g. fear of crime, typical vehicle speeds).

\section{Conclusions}

Overall the results suggest two important insights, first that there is limited relevance of familiar environments to perceptions of the unfamiliar ones, and second that there is broad generalisability of the findings though some measures could have minor sensitivity to feelings about home neighbourhood and individual traits. Hence we propose the use of adjusted mean built environment scores based on the coding system developed for the oral narratives to provide category scores for the route virtually traversed around Colchester. This could produce a navigation index (NI), the OPUS-NI that could be used as a template by local authorities in the United Kingdom. As a given locality study progresses larger groups of participants could aid in refining the weightings for the OPUS-NI sections; other researchers and planners could use/develop the approach for other northern European contexts. A possible extension would be to fuse this approach with the Pedestrian Environment Data Scan method, which was developed and implemented in Oregon (Schlossberg, 2006; Schlossberg et al., 2007; Stevens, 2005). Street audits using a handheld device similar to that employed in the Oregon Data Scan could be used to collect data on the built environment and then scored according to the OPUS-NI weighting scheme. Calculation of section scores for each street segment could be made and then divided by the number of segments to produce an overall urban landscape score. There would be no limit to values for scores for any given section, and scores may be positive or negative. Older people could be actively involved in such street audits in a form of public participation geographic information systems (GIS).

There are other findings from this study also. In terms of the relevance of the UDQ categories to navigation amongst older people, it is evident that the use of transparency and enclosure as separate items is somewhat redundant, and plausibly related to the UDQ measure being grounded in urban design theory rather than founded in the reality of the public's perceptions/'voices'. Of some note is that long walls are considered to diminish the quality of the landscape in the UDQ tool, yet the older people we consulted did not view their presence as a problem. Indeed there was a common view that they are landmarks which in fact aid navigation. This can be contrasted with SWEAT-R which was developed in conjunction with older people. Nevertheless this study also demonstrates that there is little correlation between navigation and walkability needs (see Table 2) suggesting better navigability. The team behind the Pedestrian Environment Review System, which was implemented in London, England with the co-operation of Transport for London (http://www.tfl.gov.uk), have pointed out that walkability is fundamentally about degree of usability (Stonor et al., 2003). Navigation is of course about wayfinding. The present study suggests that planners must also pay greater attention to capturing navigation needs in built environment measures to provide integrated indices of landscape quality. Developing measures of signage quality would appear to be central to this aim as Table 1 shows. Related to this is that participants in the sample showed limited ability in constructing mental maps and this is reflected in the importance of landmarks, such as long walls, in the narratives provided. Historical and distinctive buildings appear to be pivotal aspects of the built environment even more than walkability measures suggest, placing a further emphasis upon the need to conserve built environment heritage beyond those related to walkability and cultural heritage. 
A pertinent issue is that there was wide variability in oral narratives as Table 1 shows. Whilst the adjusted mean scores give insight into what the majority of older people may be thinking, careful consideration of the span of views is also important. If a place is well designed for the range of individuals in the older population, it is likely to be well designed for other groups in society too. The research presented here does have limitations. Most notably the sample size was comparatively small and the study should be considered a pilot methodological project. A minor consideration is that the provision of a map to the participants may also have skewed the patterns observed in the narratives.

\section{Acknowledgements}

The OPUS study was funded by the five Research Council New Dynamics Programme (NDA) grant number RES-352-25-0003.

We would like to thank Mark Del Aguila (Swansea University), Emmanuel Akinsola (Kingston University), Nick Brill (Kingston University), David Carswell (Swansea University), Dawn Morgan (Swansea University), Susan Scotcher (Kingston University) and Martin Spaull (Anglia Ruskin University) for their invaluable assistance throughout this project.

\section{References}

Allen, D., Clark, S., 2008. New Directions in Street Auditing: Lessons Learnt from the PERS Audits. Transport Research Laboratory, Wokingham.

Bernard, M., Phillipson, C., Phillips, J., Ogg, J., 2001. Continuity and change in the family and community life of older people. J. Appl. Gerontol. 20, 259-278.

Burton, E., Mitchell, L., 2006. Inclusive Urban Design: Streets for Life. Architectural Press, Oxford.

Clemente, O., Ewing, R., Handy, S., Brownson, R., 2005. Measuring Urban Design Qualities an Illustrated Field Manual. Robert Wood Johnson Foundation, Princeton, NJ.

Collins, P.A., Hayes, M.V., Oliver, L.N., 2009. Neighbourhood quality and self-rated health: a survey of eight suburban neighbourhoods in the Vancouver Census Metropolitan Area. Health Place 15, 156-164.

Creswell, J.W., Plano Clark, V.L., 2006. Designing and Conducting Mixed Methods Research. Sage, Thousand Oaks, CA.

Cunningham, G.O., Michael, Y.L., Farquhar, S.A., Lapidus, J., 2005. Developing a reliable senior walking environmental assessment tool. Am. J. Prev. Med. 29, 215-217.

Day, R., 2008. Local environments and older people's health: dimensions from a comparative qualitative study in Scotland. Health Place 14, 299-312.

Elsheshtawy, Y., 1997. Urban complexity: towards the measurement of the physical complexity of streetscapes. J. Archit. Plan. Res. 14, 301-316.

Ewing, R., Handy, S., Brownson, R.C., Clemente, O., Winston, E., 2006. Identifying and measuring urban design qualities related to walkability. J. Phys. Act. Health 3, S223-S240.

Foreman, N., Stanton-Fraser, D.E., Wilson, P.N., Duffy, H.E., Parnell, R., 2005. Transfer of spatial knowledge to a two-level shopping mall in older people, following virtual exploration. Environ. Behav. 37, 275-292.

Fromel, K., Mitas, J., Kerr, J., 2009. The associations between active lifestyle, the size of a community and SES of the adult population in the Czech Republic. Health Place 15, 447-454.

Giles-Corti, B., Cutt, H., Timperio, A., Pikora, T.J., Bull, F.C.L., Knuiman, M., Bulsara, M., Van Niel, K., Shilton, T., 2006. Development of a reliable measure of walking within and outside the local neighbourhood: the RESIDE project. Prev. Med. 42, 455-459.

Giles-Corti, B., Knuiman, M., Timperio, A., Van Niel, K., Pikora, T.J., Bull, F.C.L., Shilton, T., Bulsara, M., 2008. Evaluation of the implementation of a government community design policy aimed at increasing local walking: design issues and baseline results from RESIDE. Prev. Med. 46, 46-54.

Glass, T.A., Balfour, J.L., 2003. Neighbourhoods and the health of the aged. In: Kawachi, I., Berkman, L. (Eds.), Neighbourhoods and Health. Oxford University Press, Oxford, pp. 335-353.

Hartley, T., Maguire, E.A., Spiers, H.J., Burgess, N., 2003. The well-worn route and the path less travelled: distinct neural bases of route following and wayfinding in humans. Neuron 37, 877-888.

Head, D., Isom, M., 2010. Age effects on wayfinding and route learning skills. Behav. Brain Res. 209, 49-58.

Inclusive Design for Getting Outdoors, 2009a. Pedestrian-Friendly Neighbourhoods, Edinburgh. College of Art, Edinburgh.

Inclusive Design for Getting Outdoors, 2009b. Tactile Paving, Design, Siting and Laying, Edinburgh. College of Art, Edinburgh.

Jansen, P., Schmelter, A., Heil, M., 2010. Spatial knowledge acquisition in younger and elderly adults: a study in a virtual environment. Exp. Psychol. 57, 54-60.
Lee, Y., Park, K.-H., 2006. Health practices that predict recovery from functional limitations in older adults. Am. J. Prev. Med. 31, 25-31.

Leslie, E., Coffee, N., Lawrence, F., Owen, N., Bauman, A., Hugo, G., 2007. Walkability of local communities: using geographic information systems to objectively assess relevant environmental attributes. Health Place 13, 111-122.

Michael, Y., McGregor, E., 2005. Training Manual: Senior Walking Environmental Assessment Tool-Revised (SWEAT-R). Oregon Health \& Science University, Portland, Oregon.

Michael, Y., Keast, E., Chaudhury, H., Day, K., Mahmood, A., Sarte, A., 2009. Revising the senior walking assessment tool. Prev. Med. 48, 247-249.

Miles, R., Panton, L.B., Jang, M., Haymes, E.M., 2008. Residential context, walking and obesity: two African-American neighborhoods compared. Health Place 14 275-286.

Millington, C., Ward Thompson, C., Rowe, D., Aspinall, P., Fitzsimons, C., Nelson, N., Mutrie, N., 2009. Development of the Scottish Walkability Assessment Tool (SWAT). Health Place 15, 474-481.

Nielsen, T.S., Hansen, K.B., 2007. Do green areas affect health? Results from a Danish survey on the use of green areas and health indicators. Health Place 13, 839-850.

Peace, S., Kellaher, L., Holland, C., 2006. Environment and Identity in Later Life. Open University Press, Milton Keynes.

Pearce, A., Kirk, C., Cummins, S., Collins, M., Elliman, D., Connolly, A.M., Law, C. 2009. Gaining children's perspectives: a multiple method approach to explore environmental influences on healthy eating and physical activity. Health Place 15, 614-621.

Pikora, T., Giles-Corti, B., Bull, F., Jamrozik, K., Donovan, R., 2003. Developing a framework for assessment of the environmental determinants of walking and cycling. Soc. Sci. Med. 56, 1693-1703.

Pikora, T.J., Giles-Corti, B., Knuiman, M.W., Bull, F.C.L., Jamrozik, K., Donovan, R.J., 2006. Neighborhood environmental factors correlated with walking near home: using SPACES. Med. Sci. Sport Exer. 38, 708-714.

Punter, J., 2007. Developing urban design as public policy: best practice principles for design review and development management. J. Urb. Des. 12, 167-202.

Rundle, A., Field, S., Park, Y., Freeman, L., Weiss, C.C., Neckerman, K., 2008. Personal and neighborhood socioeconomic status and indices of neighborhood walkability predict body mass index in New York city. Soc. Sci. Med. 67, 19511958.

Santos, M.P., Page, A.S., Cooper, A.R., Ribeiro, J.C., Mota, J., 2009. Perceptions of the built environment in relation to physical activity in Portuguese adolescents. Health Place 15, 548-552.

Scharf, T., Phillipson, C., Smith, A., Kingston, P., 2002. Growing Older in Socially Deprived Areas. Help the Aged, London.

Scharf, T., Phillipson, C., Smith, A., 2003. Older people's perceptions of the neighbourhood: evidence from socially deprived urban areas. Sociol. Rev. Online 8 4.

Schlossberg, M., 2006. From TIGER to audit instruments: measuring neighbourhood walkability with street data based on Geographic Information Systems. Trans. Res. Rec. 1982, 48-56.

Schlossberg, M., Weinstein, A., Irvin, K., 2007. An assessment of GIS-enabled walkability audits. URISA J. 19, 5-11.

Sjolinder, M., Hook, K., Nilsson, L.-G., Anderson, G., 2005. Age differences and the acquisition of spatial knowledge in a three-dimensional environment: evaluating the use of an overview map as a navigational aid. Int. J. Hum-Comput. St. 63, 537-564.

Smith, L., Hancock, R., 2004. Do we need an age specific measure of consensual poverty for older adults? Evidence from the poverty and social exclusion survey J. Epidemiol. Commun. H. 58, 616-617.

Stahl, A., Carlsson, G., Hovbrandt, P., Iwarsson, S., 2008. Let's go for a walk! Identification and prioritisation of accessibility and safety measures involving elderly people in a residential area. Eur. J. Ageing 5, 265-273.

Stahle, A., 2010. More green space in a denser city: critical relations between user experience and urban form. Urb. Des. Int. 15, 47-67.

Stevens, R.D., 2005. Walkability around Neighborhood Parks: An Assessment of Four Parks in Springfield, Oregon. University of Oregon, Eugene, Oregon.

Stillman, T., Baumeister, R., Lambert, N., Crescioni, A., DeWall, C., Fincham, F., 2009 Alone and without purpose: life loses meaning following social exclusion. J. Exp. Soc. Psychol. 45, 686-694.

Stonor, T., de Aruda Campos, M.B., Chiaradia, A., Takamatsu, S., 2003. Towards a 'Walkability Index'. Space Syntax Limited, London.

Sugiyama, T., Leslie, E., Giles-Corti, B., Owen, N., 2008. Associations of neighbourhood greenness with physical and mental health: do walking, social coherence and local social interaction explain the relationships? J. Epidemiol. Commun. H 62 e9.

Suminski, R.R., Fritzsinger, J., Leck, T., Hyder, M.M., 2008. Observing physical activity in suburbs. Health Place 14, 894-899.

Teng, E.L., Hasegawa, K., Homma, A., Imai, Y., Larson, E., Graves, A., Sugimoto, K., Yamaguchi, T., Sasaki, H., Chiu, D., 1994. The Cognitive Abilities Screening Instrument (CASI): a practical test for cross-cultural epidemiological studies of dementia. Int. Psychogeriatr. 6, 45-58.

Tucker, P., Irwin, J.D., Gilliland, J., He, M., Larsen, K., Hess, P., 2009. Environmental influences on physical activity levels in youth. Health Place 15, 357-363.

Valdemarsson, M., Jernryd, E., Iwarsson, S., 2005. Preferences and frequencies of visits to public facilities in old age-a pilot study in a Swedish town center. Arch. Gerontol. Geriat. 40, 15-28.

Wendel-Vos, G.C., Schuit, A.J., Saris, W.H., Kromhout, D., 2003. Reproducibility and relative validity of the short questionnaire to assess health-enhancing physical activity. J. Clin. Epidemiol. 56, 1163-1169. 